Kali và duy trì nồng động trong huyết tương cao hơn mức bình thường $(4,5-5.5 \mathrm{mmol} / \mathrm{l})$ để rút ngắn khoảng QT. An thân sâu hơn có thể được chỉ định để làm giảm trương lực giao cảm, xa hơn nữa là giảm rối loạn nhịp thất [8].

\section{KẾT LUẬN}

Phần lớn bệnh nhân LQST bẩm sinh hay QT kéo dài mắc phải có thể không có dấu hiệu gì đặc biệt trong các giai đoạn gây mê hoặc can thiệp phẫu thuật. Tuy nhiên sự xuất hiện rối loạn nhịp nghiêm trọng, đặc biệt xoắn đỉnh không phải là không có. Hiện nay chưa có khuyến cáo chi tiết về gây mê hồi sức cho bệnh nhân có hội chứng QT kéo dài bẩm sinh. Sau khi nghiên cứu y văn chúng tôi muốn đưa ra một số điểm chính cần làm trong các giai đoạn của cuộc mổ, có thể là tốt nhất cho bệnh nhân có hội chứng nguy hiểm này.

\section{TÀI LIÊU THAM KHẢO}

1. Rautaharju P.M. et al. AHA/ACCF/HRS recommendations for the standardization and interpretation of the electrocardiogram: part IV: the ST segment, T and $U$ waves, and the QT interval: a scientific statement from the American
Heart Association Electrocardiography. J Am Coll Cardiol. 2009; 53: 982-991.

2. Ackerman M.J. et al. HRS/EHRA expert consensus statement on the state of genetic testing for the channelopathies and cardiomyopathies: this document was developed as a partnership between the Heart Rhythm Society (HRS) and the European Heart Rhythm Association (EHRA). Heart Rhythm. 2011; 8: 1308-1339

3. Giovanni Fazio et al. Drugs to be avoided in patients with long QT syndrome: Focus on the anaesthesiological management. World J Cardiol. 2013; 5(4): 87 - 93.

4. M. O'Hare et al. Perioperative management of patients with congenital or acquired disorders of the QT interval. British Journal of Anesthesia. 2018; 120(4): $629-644$

5. Owczuk R, Wujtewicz MA et al. The effect of intravenous lidocaine on QT changes during tracheal intubation. Anaesthesia. 2008;63:924-931

6. Karagöz AH, Basgul E, Celiker V, Aypar U. The effect of inhalational anaesthetics on QTC interval. Eur ] Anaesthesiol. 2005;22:171-174

7. Kies SJ, Pabelick CM, Hurley HA, White RD, Ackerman MJ. Anesthesia for patients with congenital long QT syndrome. Anesthesiology. 2005;102:204-210

8. Sorajja D. Et al. Optimal antiarrhythmic drug therapy for electrical storm. J Biomed Res. 2015; 29: 20-34.

\title{
TÌM HIỂU MộT SỐ YẾU TỐ LIÊN QUAN ĐẾN KẾT QUẢ PHỤC HỒI CHỨC NĂNG NHẬN THỨC TRÊN BỆNH NHÂN CHẤN THƯƠNG SỌ NÃO
}

\section{TÓM TẮT}

Suy giảm nhận thức do chấn thương sọ não có thể ảnh hưởng đến nhiều lĩnh vực bao gồm chú ý, ngôn ngữ, trí nhớ, nhận thức tri giác và chức năng điều hành. Muc tiêu: Tìm hiểu một số yếu tố liên quan đến kết quả phục hồi chức năng nhận thức trên người bênh chấn thương sọ não. Đối tượng và phương pháp nghiên cứu: Phương pháp nghiên cứu tiến cứu, so sánh kết quả trước và sau can thiệp trên 33 bệnh nhân bệnh nhân chấn thương sọ não trên 18 tuổi vào điều trị nội trú tại bệnh viện Phục hồi chức năng Hà Nội. Kết quả và kết luận: Bệnh nhân chấn thương sọ não chủ yếu là nam giới chiểm tỷ lệ $78,8 \%$, nữ giới chiếm 21,2\%, tỷ lệ nam/nữ là 3.71/1. Độ tuổi và giới tính không ảnh hưởng đến phục hồi chức năng nhận thức của bệnh nhân chấn thương sọ não $(p>0,05)$. Những bệnh nhân có thời gian mắc bệnh dưới 6 tháng và trển 6 tháng không ảnh hưởng đến PHCN nhận

\section{*Trường Đại học Y Hà Nội}

Chịu trách nhiệm chính: Phạm Văn Minh

Email: pvminhrehab@yahoo.com

Ngày nhận bài: 6.5.2021

Ngày phản biện khoa học: 25.6.2021

Ngày duyệt bài: 6.7.2021
Phạm Văn Minh*, Phan Thị Kiều Loan*

thức của bệnh nhân chấn thương sọ não ( $p>0,05)$.

Tư khóa: Yếu tố liên quan, Phục hồi chức năng nhận thức, Chấn thương sọ não

\section{SUMMARY \\ FINDING SOME FACTORS RELATED TO THE EFFECTIVENESS OF COGNITIVE \\ REHABILITATION FOR PATIENTS WITH TRAUMATIC BRAIN INJURY}

Cognitive impairment due to traumatic brain injury can affect many areas including attention, language, memory, perceptual cognition, and executive function. Objective: To find some factors related to the outcome of cognitive rehabilitation in patients with traumatic brain injury. Patients and methodology: Prospective research method, comparing results before and after treatment on 33 patients with traumatic brain injury over 18 years old admitted to inpatient treatment at Ha Noi Rehabilitation Hospital. Results and conclusions: Most of the traumatic brain injury patients were male, accounting for $78.8 \%$, female accounted for $21.2 \%$, male/female ratio was 3.71/1. Age and gender did not affect cognitive rehabilitation of traumatic brain injury patients $(p>0.05)$. Patients with disease duration less than 6 months and more than 6 months did not affect 
cognitive rehabilitation of traumatic brain injury patients $(p>0.05)$

Key word: Factors related, Cognitive rehabilitation, Traumatic brain injury

\section{I. ĐẶT VẤN ĐỀ}

Theo số liệu của tổ chức $Y$ tế thế giới, hàng năm tại Việt Nam chấn thương sọ não (CTSN) là nguyên nhân dẫn đến tử vong xếp hàng thứ tư, làm 21.000 người chết trong năm 2012 (theo WHO, 2015). CTSN là một trong những nguyên nhân hàng đầu gây ra khuyết tật ở Hoa Kỳ, ước tính khoảng 13,5 triệu người chịu ảnh hưởng [1]. Người sống sót thường có những khiếm khuyết, ảnh hưởng nhiều đến cuộc sống của họ và gia đình.

Suy giảm nhận thức do CTSN có thể ảnh hưởng đến nhiều lĩnh vực bao gồm chú ý, ngôn ngữ, trí nhớ, nhận thức tri giác và chức năng điêu hành. Suy giảm nhận thức thể hiện rõ khi họ khó hoạt động và hòa nhập xã hội. Nghiên cứu dịch tế học chỉ ra rằng khoảng $43 \%$ số bệnh nhân bị khuyết tật trong thời gian 6 tháng hoặc lâu hơn, được đặc trưng bởi hạn chế chức năng hoạt động và/hoặc các vân đề về sức khỏe tâm thần ${ }^{4}$. Gần đây một phần tư bệnh nhân CTSN từ trung bình đến nặng không thể trở lại làm việc trong năm đầu sau chấn thương [2].

Điều trị cho sự rối loạn này bao gồm điều trị thuốc và phục hồi chức năng trong đó $\mathrm{PHCN}$ nhận thức được nhấn mạnh là đem lại hiệu quả đáng kể và cần được can thiệp sớm [3]. Tại Việt Nam hiện nay các đề tài về $\mathrm{PHCN}$ chủ yếu là các nghiên cứu về đánh giá mức độ PHCN vận động chứ chưa đề cập đến nhận thức đặc biệt là tìm hiểu các yếu tố liên quan đến kết quả phục hồi chức năng nhận thức trên người bệnh chấn thương sọ não. Vì vậy chúng tôi tiến hành nghiên cứu: Tìm hiểu một số yếu tố liên quan đến kết quả phục hồi chức năng nhận thức trên người bệnh chấn thương sọ não tại Bệnh viện Phục hồi chức năng Hà Nội.

\section{II. ĐỐI TƯỢNG VÀ PHƯƠNG PHÁP NGHIÊN CỨU}

2.1. Địa điểm và thời gian nghiên cứu

- Địa điểm: Bệnh viện Phục hồi chức năng Hà Nội

- Thời gian: Từ tháng 8/2019 đến tháng 11/2020

2.2. Đối tượng nghiên cứu. 33 bệnh nhân bệnh nhân chấn thương sọ não trên 18 tuổi vào điều trị nội trú tại bệnh viện Phục hồi chức năng HN.

\subsubsection{Tiêu chuẩn lựa chọn}

Bệnh nhân đủ điều kiện tiếp nhận điều trị tại bệnh viện Phục hồi chức năng Hà Nội:

- Bệnh nhân bị CTSN giai đoạn hồi phục.

- Gia đình và bệnh nhân đồng ý tham gia nghiên cứu.
- Bệnh nhân có thể ngồi được trên ghế kể cả có sự trợ giúp.

- Fugl - Meyer Arm Test từ 25 điểm trở lên.

- Bệnh nhân không bị thất ngôn.

\subsubsection{Tiêu chuẩn loại trừ}

- Bệnh nhân CTSN mà trước đó có bệnh lý kèm theo liên quan đến nhận thức như suy giảm nhận thức do bệnh Parkinson, Alzheimer.

- Bệnh nhân không có điều kiện và thời gian tham gia vào nghiên cứu.

- Gia đình và bệnh nhân không đồng ý tham gia nghiên cứu.

\subsection{Phương pháp nghiên cứu}

2.3.1. Thiết kế nghiên cứu. Phương pháp nghiên cứu tiến cứu, so sánh kết quả trước và sau can thiệp

2.3.2. Các thành phân của chương trình PHCN nhận thức. Chương trình PHCN nhận thức cho bệnh nhân CTSN toàn diện bao gồm lượng giá bệnh nhân, vận động trị liệu, hoạt động trị liệu và ngôn ngữ trị liệu.

Lượng giá bệnh nhân. Trước khi tham gia tập PHCN nhận thức, bệnh nhân được đánh giá thông qua hỏi bệnh, khám lâm sàng, chức năng nhận thức, chức năng sinh hoạt qua thang đánh giá độc lập chức năng (FIM). Và đánh giá lại 1 tháng/ lần.

Vận động trị liệu. Các bài tập vận động trị liệu tuy không tác động chính đến tập nhận thức tuy nhiên các bài tập này giúp người bệnh kiểm soát tư thế, tăng cường sức mạnh cơ và khả năng điều hợp thần kinh cơ. Đẩy là bước tạo thuận cho người bệnh được PHCN nhận thức toàn diện.

Hoạt động trị liệu. Đóng vai trò quan trọng trong PHCN nhận thức cho bệnh nhân, các bài tập hoạt động kích thích kỹ năng tri giác, nắm bắt sự vật và thiết lập hoạt động khi được hướng dẫn và tập luyện.

Ngôn ngữ trị liệu. Các bài tập ngôn ngữ trị liệu có sự hướng dẫn, trao đổi thông tin bằng lời nói tích cực với KTV, giúp người bệnh luyện tập được khả năng ghi nhớ, giao tiếp và xử lý thông tin. Đây là phương pháp không thể thiếu trong tập PHCN nhận thức cho bệnh nhân.

2.4. Các kỹ thuật can thiệp sử dụng trong nghiên cứu. Khi bắt đầu chương trình PHCN, BN sẽ được lượng giá về chức năng nhận thức và vận động. Những BN bị suy giảm nhận thức trên lĩnh vực nào sẽ được tập các bài tập trên các lĩnh vực đó, tập trung vào những kỹ năng mình cần cải thiện, mỗi buổi tập được điều tri về hai vấn đề của bệnh nhân, khi bênh nhân đã đạt được bài tập đơn giản, họ sẽ được điều 
trị lên mốc bài tập cao hơn, độ phức tạp khó hơn đò̀ hỏi sự điêuu hợp, mức độ tinh vi và kết hợp các kỹ năng với nhau.

\section{KẾT QUẢ NGHIÊN CỨU}

3.1. Phân bố về độ tuổi, giới của đối tượng nghiên cứu

Bảng 3.1. Đặc điểm về tuổi, giới

\begin{tabular}{|c|c|c|c|}
\hline Giới & n & $\begin{array}{c}\text { Trung } \\
\text { bình }\end{array}$ & $\begin{array}{c}\text { Độ lệ̂h } \\
\text { chuẩn }\end{array}$ \\
\hline Nam & 26 & 37,17 & 15,93 \\
\hline
\end{tabular}

\begin{tabular}{|c|c|c|c|}
\hline Nữ & 7 & 30,22 & 11,73 \\
\hline Tống & $\mathbf{3 3}$ & $\mathbf{3 5 , 2 7}$ & $\mathbf{1 5 , 0 5}$ \\
\hline
\end{tabular}

Nhận xét: Bệnh nhân chấn thương sọ não chủ yếu là nam giới chiếm tỷ lệ $78,8 \%$, nữ giới chiếm 21,2\%, tỷ lệ nam/nữ là 3.71/1.

Độ tuổi trung bình bị CTSN của nam giới là $37,17 \pm 15,93$, của nữ giới là $30,22 \pm 11,73$ và của toàn bộ nhóm bệnh nhân tham gia nghiên cứu là 35,27士 15,05 tuổi.

3.2. Liên quan giữa tuổi và cải thiện chức năng nhận thức theo FIM

Bảng 3.2. Liên quan giữa tuổi và cải thiện chức năng nhận thức theo FIM

\begin{tabular}{|c|c|c|c|c|c|}
\hline \multirow{2}{*}{ Nhóm tuổi Chức năng nhận thức } & \multicolumn{2}{|c|}{ Độc lập } & \multicolumn{2}{|c|}{ Phụ thuộc một phân } & \multirow[b]{2}{*}{ p } \\
\hline & $\mathbf{S L}$ & $\%$ & SL & $\%$ & \\
\hline$<20$ & 0 & 0 & 1 & 5,3 & \multirow{3}{*}{$>0,05$} \\
\hline $20-60$ & 13 & 92,9 & 15 & 78,9 & \\
\hline$>60$ & 1 & 7,1 & 3 & 15,8 & \\
\hline
\end{tabular}

Nhận xét: Không có mối liên quan giữa tuối và kết quả cải thiện chức năng nhận thức của người bệnh với $p>0,05$

3.3. Liên quan giữa giới tính và cải thiện chức năng nhận thức theo FIM

Bảng 3.3. Liên quan giữa giới tính và cải thiện chức năng nhận thức theo FIM

\begin{tabular}{|c|c|c|c|c|c|}
\hline \multirow{2}{*}{ Chức năng Giới tính } & \multicolumn{2}{|c|}{ Nam } & \multicolumn{2}{|c|}{ Nữ } & \multirow[b]{2}{*}{ p } \\
\hline & SL & $\%$ & SL & $\%$ & \\
\hline Độc lập & 12 & 46,2 & 1 & 14,3 & \\
\hline Phụ thuộc một phần & 14 & 53,8 & 6 & 85,6 & 0,536 \\
\hline
\end{tabular}

Nhận xét: Không có mối liên quan giữa giới tính và kết quả cải thiện chức năng vận động của người bệnh với $p>0,05$

3.4. Liên quan giữa thời gian bị bệnh và cải thiện chức năng nhận thức theo FIM

Bảng 3.4. Liên quan giữa thời gian bị bệnh đến kết quả PHCN nhận thức

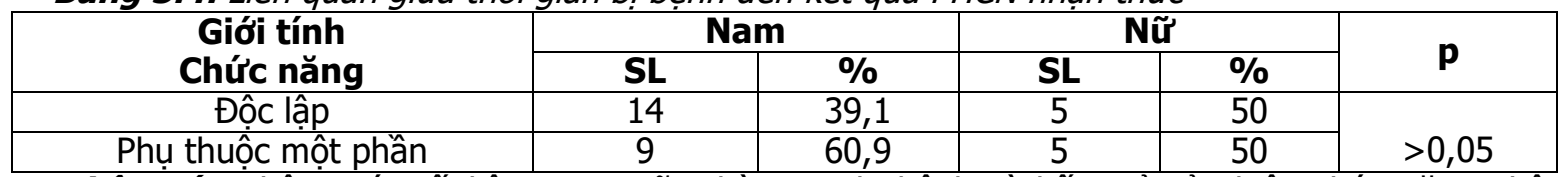

Nhận xét: Không có mối liên quan giữa thời gian bị bệnh và kết quả cải thiện chức năng nhận thức cưa người bệnh với p> 0,05.

\section{BÀN LUÂ̂N}

4.1. Đặc điểm chung của đối tượng nghiên cứu. Trong nghiên cứu của chúng tôi thấy tỷ lệ nam/nữ bị chấn thương sọ não là $3,71 / 1$, (nam chiếm 78,8\%, nữ chiếm 21,2\%). Đặc điểm này phù hợp với tình hình dịch tễ chung của chấn thương sọ não. Trong nghiên cứu của Nguyễn Tuấn Anh và Lưu Sỹ Hùng trên 55 bệnh nhân, nam giới gấp 2,44 lần nữ giới [4]. Theo nghiên cứu Hoffman, tỷ lệ nam CTSN cao hơn nữ (73\% so với 27\%) [5]. Điêu này có thể giải thích do hầu hết bênh nhân đều là nam. Họ là trụ cột gia đình cũng như có nhiều mối giao lưu hơn phụ nữ. Thường phải đi ra ngoài nhiều do tính chất công việc và quan hệ đối tác bạn bè. Khi đó, nam giới có nhiều cơ hội tham gia giao thông nhiều, làm những công việc mạo hiểm hơn.
Đô tuổi trung bình của bênh nhân CTSN trong nghiên cứu này là $35,27 \pm 15,05$ tuổi. BN có tuổi thấp nhất là 18 tuổi, BN nhiều tuổi nhất là 72 tuổi. Độ tuổi trung bình của bệnh nhân nam là $37,17 \pm 15,93$ tuổi, của nữ là 30,22 $\pm 11,73$ tuổi. Kết quả này tương đồng với nghiên cứu của Nguyễn Tuấn Anh và Lưu Sỹ Hùng với tuổi trung bình là 36,13 tuổi. Theo nghiên cứu của Bazarian và CS trên 1425 bệnh nhân năm 2010 tại Mỹ cho kết quả độ tuổi trung bình là 46,26 tuổi, trong đó nữ tuổi trung bình là 28,8 tuối, nam là 31,6 tuổi. Có sự khác biệt này có thể do nghiên cứu của chúng tôi có cỡ mẫu nhỏ nên tính đại diện chưa cao.

4.2. Mối liên quan giữa tuổi và hiệu quả PHCN. Điểm chệnh lệch trung bình theo tổng điểm FIM của nhóm tuổi từ 20 - 60 là 10,28 \pm 6,9, trong khi đó chênh lệch tổng điểm FIM 
trung bình của nhóm tuổi > 60 là $5 \pm 5,65$, nhóm dưới 20 tuổi chỉ có 1 người với chênh lệch điểm là 8 . Tuy nhiên, sự khác biệt này giữa các nhóm tuổi không có ý nghĩa. Kết quả này khác với nghiên cứu của $A L$ Yazeedi $W$ và $C S$ tại Qutar, cho rằng bệnh nhân CTSN cao tuổi có hiệu quả PHCN chậm hơn những bệnh nhân trẻ tuổi [6]. Điều này có thể giải thích do chức năng não suy giảm, dễ bị lão hóa ở những bệnh nhân lớn tuổi hoăcc giảm khả năng mềm dẻo thần kinh và chấp nhận bệnh tật, tham gia tích cực vào các buổi PHCN nhân thức. Có sự khác biệt ở đề tài chúng tôi có thể do cõ mẫu trong nghiên cứu của chúng tôi còn nhỏ, chưa có tính đại diện cho cả quần thể.

4.3. Liên quan của giới tính và hiệu quả PHCN nhận thức. Nam giới dường như có sự sang chân tâm lý nhiều hơn nữ giới về sự chấp nhận rủi ro, nhận thức về những vấn đề mình bị liệt hay không còn minh mẫn như trước. Dấn đến bệnh nhân dễ chán nản, có nhiêu khả năng bị các triệu chứng liên quan đến tinh thần như trầm cảm và mệt mỏi, điều này có thể gián tiếp tác động tiêu cực đến sự PHCN nhận thức của bệnh nhân sau CTSN.

Nghiên cứu của chúng tôi chưa tìm được ra mối liên quan giữa giới tính và kết quả cải thiện chức năng nhận thức của bệnh nhân với p>0,05. Theo như nghiên cứu Niemeier JP và CS trên 121 bênh nhân trong đó có 81 nam và 40 nữ cho thấy nam giới trước khi bị CTSN tự đánh giá năng lực lớn hơn các thành viên trong gia đình và kéo dài đến khi bị chấn thương, bệnh nhân khó chấp nhận năng lực của mình yếu hơn hay ngang bằng với họ. Trong khi nữ giới sau CTSN, khả năng của họ yếu hơn hoặc ngang bằng với các thành viên gia đình. Họ có nhận thức tốt hơn về mức thâm hụt của bản thân sau CTSN. Do đó họ tích cực tham gia chương trình PHCN [7].

4.4. Mối liên quan giữa thời gian bị bệnh và hiệu quả PHCN. Thời gian bị bệnh càng kéo dài thì bệnh nhân càng dể gặp các biến chứng và thương tật thứ cấp như teo cơ, cứng khớp, nhiễm khuẩn, cũng như khả năng hồi phục thần kinh bị trì trệ, cơ thể dần quen với sự thiếu sót, suy giảm của não bộ trong các giao tiếp, sinh hoạt hàng ngày... khiến việc điều trị gặp nhiều khó khăn. Những bệnh nhần từ khi bị bệnh đến khi vào viện trong khoảng thời gian dưới 6 tháng có mức thay đổi theo tổng điểm FIM là 11,06 \pm 7,29. Với những bệnh nhân có thời gian vào viện trên 6 tháng có mức thay đổi là $7,1 \pm 4,88$. Tuy nhiên, sự khác biệt này giữa các nhóm này không có ý nghĩa thống kê.
Theo nghiên cứu của Demir và CS năm 2019 cho thấy thời gian bị bệnh có liên quan đáng kể đến khả năng $\mathrm{PHCN}$ nhận thức của bệnh nhân CTSN [8]. Có sự khác biệt này có thể do thời gian nghiên cứu của Demir lâu hơn và cõ mẫu lớn hơn nghiên cứu của chúng tôi chỉ tiến hành trong 1 tháng. Vì vậy, chưa phản ánh được mối liên quan từ lúc bệnh nhân bị bệnh đến khi vào viện. Nhiều bệnh nhân chưa biết nhiều đến PHCN nhận thức, người nhà cho rằng người thân mình bị bệnh có khả năng cử động chân tay là có thể về nhà được, tuy nhiên khi về nhà những bênh nhân này chỉ ở nhà phụ thuộc hoàn toàn, không biết làm gì vì các chức năng nhận thức như trí nhớ, ngôn ngữ, khả năng giải quyết vấn đề không được cải thiện, rất khó có thể quay lại công việc như trước khi bị bệnh. Bệnh cạnh đó, họ cũng không được chuyên gia PHCN lượng giá, xem xét để đưa ra công việc phù hợp và hướng dẫn họ làm những công việc đó có thể đem lại thu nhập cá nhân, tránh tình trạng phải phụ thuộc vào người nhà và xã hội.

\section{KẾT LUÂN}

- Độ tuổi và giới tính không ảnh hưởng đến PHCN nhận thức của bệnh nhân CTSN $(p>0,05)$.

- Những bệnh nhân có thời gian mắc bệnh dưới 6 tháng và trên 6 tháng không ảnh hưởng đến PHCN nhận thức của bệnh nhân CTSN ( $p>$ $0,05)$.

\section{TÀI LIẸU THAM KHẢO}

1. Coronado V, McGuire $L$, Faul $M$, et al (2012). Epidemiology and public health issues. In: Brain Injury Medicine: Principles and Practice. Published online.

2. Bô̂ Y tế (2018). Hướng dẫn chẩn đoán, điều trị phục hồi chức năng cho người bệnh chấn thương sọ não, Nhà Xuất Bản Y Học, Hà Nội.; 2018.

3. Arciniegas DB, Held $\dot{K}$, Wagner $P$ (2002). Cognitive Impairment Following Traumatic Brain

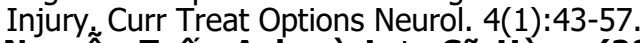

4. Nguyễn Tuấn Anh và Lưu Sỹ Hùng (2017). Nghiên cứu hình thái học của tồn thương dập não do tai nạn giao thông đường bộ qua giám định pháp y. Tap chí Khoa hoc ĐHQGHNiN.

5. Hoffman JM, Lucas S, Dikmen S, Temkin N (2020). Clinical Perspectives on Headache After Traumatic Brain Injury. PM R. 12(10):967-974.

6. Al Yazeedi W, Venkatachalam L (2010). Factors Influencing Rehabilitation Outcome in Adult Traumatic Brain Injury in Qatar. Published online.

7. Niemeier JP, Perrin $P B$, Holcomb $M G$, et al (2014). Gender Differences in Awareness and Outcomes During Acute Traumatic Brain Injury Recovery. J Womens Health. 23(7):573-580.

8. Demir $Y$, Köroğlu Ö, Tekin E, et al (2019). Factors affecting functional outcome in patients with traumatic brain injury sequelae: Our singlecenter experiences on brain injury rehabilitation. Turk J Phys Med Rehabil. 65(1):67. 